\title{
Afterload reduction treatment for large ventricular septal defects \\ Dependence of haemodynamic effects of hydralazine on pretreatment systemic blood flow
}

\author{
MAKOTO NAKAZAWA, ATSUYOSHI TAKAO, TAKASHI SHIMIZU, YONG CHON \\ From the Department of Pediatric Cardiology, The Heart Institute of fapan, Tokyo Women's Medical College, \\ Tokyo, fapan
}

SUMMARY The haemodynamic effects of hydralazine were studied in seven infants and a child, each with a large ventricular septal defect. Hydralazine, $0.3 \mathrm{mg} / \mathrm{kg}$, was administered intravenously. This caused a lowering of pulmonary arterial pressure from $57 \pm 4 \mathrm{mmHg}$ to $49 \pm 4 \mathrm{mmHg}$, and a lowering of left atrial pressure from $12 \pm 1 \mathrm{mmHg}$ to $10 \pm 1 \mathrm{mmHg}$. Systemic vascular resistance was reduced from $19 \cdot 0 \pm 2.4$ units $/ \mathrm{m}^{2}$ to $15 \cdot 1 \pm 0.9$ units $/ \mathrm{m}^{2}$. Pulmonary vascular resistance was reduced in six cases and increased in two. Systemic blood flow (Qs) increased in six cases and was unchanged in one. It decreased in one case where the pretreatment Qs was high, that is $6.4 \mathrm{l} / \mathrm{min}$ per $\mathrm{m}^{2}$. Pulmonary blood flow (Qp) increased in six cases while it decreased in two. These two cases had a pretreatment Qs less than $3.0 \mathrm{l} / \mathrm{min}$ per $\mathrm{m}^{2}$. The pulmonary to systemic blood flow ratio $(\mathrm{Qp} / \mathrm{Qs}$ ratio) decreased only in three patients who had Qs less than $3.0 \mathrm{l} / \mathrm{min}$ per $\mathrm{m}^{2}$ before hydralazine. In contrast, the $Q p / Q$ s ratio increased in the five cases with higher pretreatment $Q s$. Thus, this study has found that the pretreatment $Q s$ alters the effect of hydralazine on the $Q p / Q s$ ratio in large ventricular septal defects, thus indicating that afterload reduction treatment with hydralazine may be effective in the management of large ventricular septal defects by reducing the Qp/Qs ratio in the cases that are associated with a low systemic blood flow.

Vasodilators are effective in the management of compromised cardiac performance which is secondary to various heart diseases such as primary or ischaemic congestive cardiomyopathy, and mitral and/or aortic regurgitation..$^{1-6}$ It has been suggested that a reduction of systemic vascular resistance in large ventricular septal defects results in an increase of the flow through the aortic outflow tract, while the flow through the septal defect decreases or stays constant, which leads to a decrease in the pulmonary to systemic flow ratio $(\mathrm{Qp} / \mathrm{Qs}$ ratio). This has been supported by animal experiment ${ }^{7}$ and clinical study. ${ }^{8}$ The subjects studied in those reports, however, do not necessarily represent the haemodynamic condition which we often observe in infants with a large ventricular septal defect. This study was therefore undertaken to evaluate the effects of afterload reduc-

Accepted for publication 3 February 1983 tion treatment in infants and younger children with a large ventricular septal defect who have been admitted to hospital for surgical treatment.

\section{Subjects and methods}

Eight patients with an isolated ventricular septal defect were the subjects of this study. The clinical and basic haemodynamic data are summarised in Table 1. Seven cases were under 12 months of age. One case older than this was included because of an important observation, which will be discussed later. This case had tachypnoea, small peripheral pulses, pronounced perspiration, and pale skin. All the patients were admitted to hospital for surgical treatment because they had had frequent respiratory tract infections, pulmonary hypertension, or had failed to thrive. Informed consent was obtained for this study. All patients received pethidine- $\mathrm{HCl}, 1 \mathrm{mg} / \mathrm{kg}$, and hyd- 
Table 1 Clinical and basic haemodynamic data

\begin{tabular}{|c|c|c|c|c|c|c|c|c|}
\hline & Age (mth) & Sex & Weight $(K g)$ & Resp. rate & $\mathrm{P}_{\mathrm{a}} \mathrm{CO}_{2}$ & $R V P / L V P$ & $Q p / Q s$ & Liver (cm) \\
\hline $\begin{array}{l}1 \\
2 \\
3 \\
4 \\
5 \\
6 \\
7 \\
8\end{array}$ & $\begin{array}{r}4 \\
11 \\
6 \\
5 \\
11 \\
2 \\
5 \\
20\end{array}$ & $\begin{array}{l}M \\
M \\
M \\
F \\
F \\
M \\
F \\
M\end{array}$ & $\begin{array}{l}5.5 \\
8.0 \\
5.4 \\
5.6 \\
7.7 \\
4.2 \\
6.0 \\
9.5\end{array}$ & $\begin{array}{l}45 \\
48 \\
53 \\
50 \\
55 \\
56 \\
44 \\
36\end{array}$ & $\begin{array}{l}50 \\
47 \\
43 \\
36 \\
40 \\
47 \\
32 \\
37\end{array}$ & $\begin{array}{l}75 / 96 \\
82 / 76 \\
94 / 90 \\
85 / 102 \\
75 / 83 \\
70 / 100 \\
56 / 68 \\
77 / 100\end{array}$ & $\begin{array}{l}2.4 \\
3 \cdot 5 \\
1.8 \\
1.8 \\
2.5 \\
4 \cdot 2 \\
3 \cdot 1 \\
4 \cdot 7\end{array}$ & $\begin{array}{l}3 \\
2 \\
3 \\
2 \\
3 \\
3 \\
3 \\
1\end{array}$ \\
\hline
\end{tabular}

RVP/LVP, peak right ventricular pressure/peak left ventricular pressure; Qp/Qs, pulmonary to systemic blood flow ratio.

roxyzine pamoate, $1 \mathrm{mg} / \mathrm{kg}, 30$ minutes before the study. Right and left heart catheterisation was performed to measure intracardiovascular pressure, systemic and pulmonary blood flow (Qs and Qp, respectively), and systemic and pulmonary vascular resistance. This was done before and 10 to 20 minutes after intravenous administration of hydralazine ( 0.3 $\mathrm{mg} / \mathrm{kg}$ ). Oxygen consumption was measured using a continuous flow-through system. ${ }^{9}$ Then angiography was carried out to confirm the presence of an isolated ventricular septal defect in each patient. The data were analysed by the paired $t$ test. All values are expressed as mean \pm standard error of the mean.

\section{Results}

CHANGES IN INTRACARDIOVASCULAR PRESSURE Mean aortic pressure fell in only three cases and then only by $26 \%$ at the most, but the mean of the eight patients did not change significantly. Mean pulmonary arterial pressure fell significantly from $57 \pm 4$ $\mathrm{mmHg}$ to $49 \pm 4 \mathrm{mmHg}(\mathrm{p}<0.01)$. Mean left atrial pressure fell in all but one case in whom the pressure did not change. The mean changed from $12 \pm 1$ $\mathrm{mmHg}$ to $10 \pm 1 \mathrm{mmHg}(\mathrm{p}<0.05)$. Mean right atrial pressure fell in seven patients but was increased in one (Fig. 1).

\section{CHANGES IN VASCULAR RESISTANCE}

Systemic vascular resistance was reduced from $19.0 \pm 2.4 \mathrm{mmHg} / 1$ per $\min$ per $\mathrm{m}^{2}$ (units $/ \mathrm{m}^{2}$ ) to $15.1 \pm 0.9$ units $/ \mathrm{m}^{2}(\mathrm{p}<0.05)$. The change was larger in cases where the prehydralazine systemic vascular resistance was 20 units $/ \mathrm{m}^{2}$ or higher than in cases with a lower such resistance. Pulmonary vascular resistance decreased in six but increased in two. The mean changed from $4.5 \pm 0.6 \mathrm{units} / \mathrm{m}^{2}$ to $3.6 \pm 0.7$ units $/ \mathrm{m}^{2}(0.05<\mathrm{p}<0.1)$ (Fig. 2).

\section{CHANGES IN SYSTEMIC AND PULMONARY BLOOD}

FLOW AND QP/QS RATIO

Systemic blood flow increased in six cases and stayed constant in one. In the remaining case, it was 6.4 $1 / \mathrm{min}$ per $\mathrm{m}^{2}$ before hydralazine and changed to 5.6 $\mathrm{l} / \mathrm{min}$ per $\mathrm{m}^{2}$ after the drug. The change in the mean in the whole series, from $3.8 \pm 0.51 / \mathrm{min}$ per $\mathrm{m}^{2}$ to $4.3 \pm 0.31 / \mathrm{min}$ per $\mathrm{m}^{2}$, was not statistically significant $(0.05<\mathrm{p}<0.1)$. Pulmonary blood flow increased in six cases, and decreased in two. These two cases had pretreatment Qs of $3.0 \mathrm{l} / \mathrm{min}$ per $\mathrm{m}^{2}$ or less. The mean did not significantly alter $\left(10.5 \pm 0.9 \mathrm{l} / \mathrm{min}\right.$ per $\mathrm{m}^{2}$ to $13.4 \pm 2.5 \mathrm{l} / \mathrm{min}$ per $\mathrm{m}^{2} ; \mathrm{p}=0 \cdot 1 ;$ Fig. 3 ). No significan change was observed in the $\mathrm{Qp} / \mathrm{Qs}$ ratio in the series as a whole. This ratio, however, was reduced in the three patients who had the Qs of $3.0 \mathrm{l} / \mathrm{min}$ per $\mathrm{m}^{2}$ or

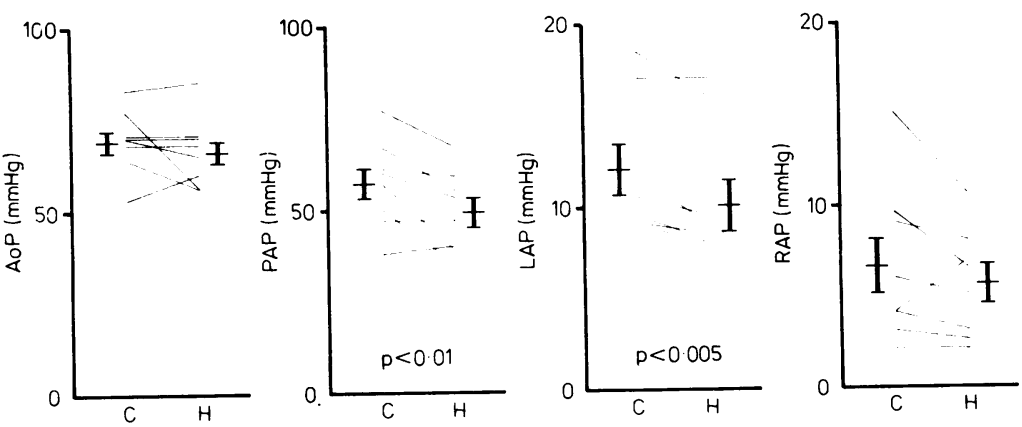

Fig. 1 Changes in intracardiovascular pressure after hydralazine. Mean pulmonary arterial and left atrial pressure (PAP and LAP) were significantly decreased. AoP, mean aortic pressure; $R A P$, mean right atrial pressure; $C$, control; $H, 20$ minutes after hydralazine. 

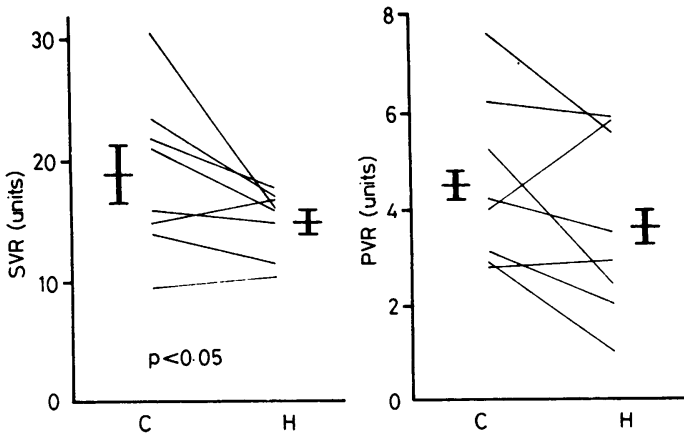

Fig. 2 Effects of hydralazine on systemic and pulmonary resistance. Systemic vascular resistance (SVR) was significantly reduced. The reduction was larger in cases with high prehydralazine value than in cases with low SVR. Pulmonary vascular resistance (PVR) showed decrease in six cases and increase in two cases. $C$, control; $H$, hydralazine.
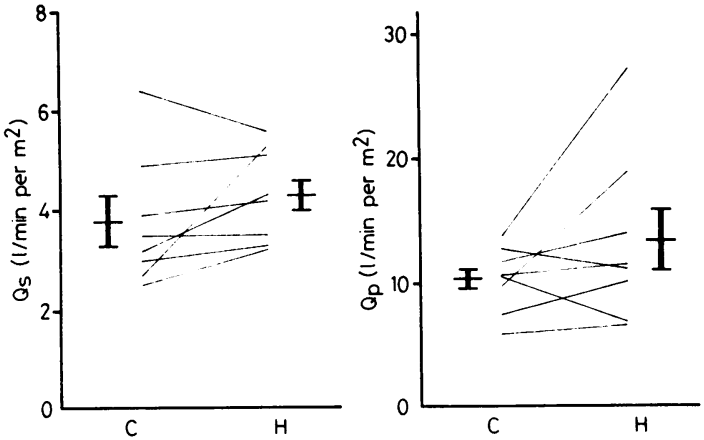

Fig. 3 Effects of hydralazine on systemic and pulmonary blood flow in patients with large ventricular septal defect. Systemic blood flow (Qs) was increased in all but one case, which had a very high prehydralazine $Q$ s. Pulmonary blood flow $(Q p)$ was increased in six patients and was decreased in two. $C$, control; $H$, hydralazine.

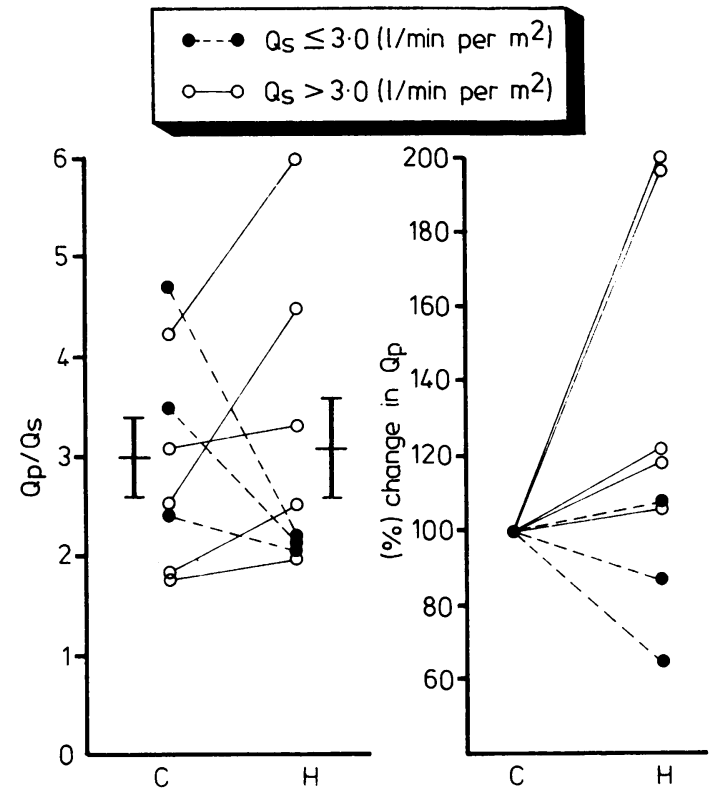

Fig. 4 Effects of hydralazine in the $Q p / Q$ s ratio and on the percentage change in pulmonary blood flow. In cases with low systemic blood flow, the flow ratio was reduced and pulmonary blood flow was also reduced or at least not significantly increased. $C$, control; $H$, hydralazine.

less before hydralazine, and the reduction was associated with a decrease or minimal increase in the Qp. On the other hand, the $\mathrm{Qp} / \mathrm{Qs}$ ratio increased in the five patients who had the higher Qs and this was associated with a significant increase in Qp (Fig. 4, Table 2).

Table 2 Effects of hydralazine on haemodynamics in ventricular septal defect

\begin{tabular}{|c|c|c|c|c|c|c|c|c|c|c|c|c|c|c|c|c|c|c|c|}
\hline \multirow[t]{2}{*}{$\begin{array}{l}\text { Case } \\
\text { No. }\end{array}$} & \multirow[t]{2}{*}{$\begin{array}{l}\text { Age } \\
\text { (mth) }\end{array}$} & \multicolumn{2}{|c|}{$\begin{array}{l}S A P \\
(m m H g)\end{array}$} & \multicolumn{2}{|c|}{$\begin{array}{l}P A P \\
(m m H g)\end{array}$} & \multicolumn{2}{|c|}{$\begin{array}{l}L A P \\
(m m H g)\end{array}$} & \multicolumn{2}{|c|}{$\begin{array}{l}R A P \\
(m m H g)\end{array}$} & \multicolumn{2}{|c|}{$\frac{Q p}{\left(1 / \min \text { per } m^{2}\right.}$} & \multicolumn{2}{|c|}{$\begin{array}{l}\text { Qs } \\
\left(1 / \text { min per } m^{2}\right)\end{array}$} & \multicolumn{2}{|c|}{$\begin{array}{l}P V R \\
\text { (units/m²) }\end{array}$} & \multicolumn{2}{|c|}{$\begin{array}{l}S V R \\
\left.\text { (units } / m^{2}\right)\end{array}$} & \multicolumn{2}{|c|}{$Q p / Q s$} \\
\hline & & $C$ & $H$ & $C$ & $H$ & $C$ & $H$ & $C$ & $H$ & $C$ & $H$ & $C$ & $H$ & $C$ & $H$ & $C$ & $H$ & $C$ & $H$ \\
\hline $\begin{array}{l}2 \\
3 \\
4 \\
5 \\
6 \\
7 \\
8 \\
8\end{array}$ & $\begin{array}{r}4 \\
11 \\
6 \\
5 \\
11 \\
2 \\
5 \\
20\end{array}$ & $\begin{array}{l}64 \\
70 \\
77 \\
70 \\
68 \\
70 \\
53 \\
83\end{array}$ & $\begin{array}{l}56 \\
70 \\
57 \\
65 \\
68 \\
70 \\
60 \\
85\end{array}$ & $\begin{array}{l}47 \\
67 \\
77 \\
61 \\
60 \\
50 \\
38 \\
57\end{array}$ & $\begin{array}{l}47 \\
55 \\
67 \\
59 \\
53 \\
35 \\
40 \\
39\end{array}$ & $\begin{array}{r}9.5 \\
18.5 \\
11.5 \\
10.5 \\
9 \\
9 \\
8 \\
17\end{array}$ & $\begin{array}{c}8 \\
16 \\
9 \\
9 \cdot 5 \\
8 \\
8 \cdot 5 \\
7 \\
17\end{array}$ & $\begin{array}{c}4 \\
15 \\
9 \\
9 \cdot 5 \\
6 \\
2 \\
3 \\
4\end{array}$ & $\begin{array}{l}3 \\
10.5 \\
8 \\
6 \cdot 5 \\
5 \\
2 \\
2 \cdot 5 \\
7\end{array}$ & $\begin{array}{r}6.1 \\
10.5 \\
8.6 \\
11.8 \\
9.7 \\
13.8 \\
10.8 \\
12.8\end{array}$ & $\begin{array}{r}6.6 \\
6.9 \\
10.2 \\
14.2 \\
18.8 \\
27.7 \\
11.5 \\
11.2\end{array}$ & $\begin{array}{l}2.5 \\
3.0 \\
4.9 \\
6.4 \\
3.9 \\
3.2 \\
3.5 \\
2.7\end{array}$ & $\begin{array}{l}3.2 \\
3.3 \\
5.1 \\
5.6 \\
4.2 \\
4.3 \\
3.5 \\
5.3\end{array}$ & $\begin{array}{l}6.2 \\
4.0 \\
7.6 \\
4.2 \\
5.3 \\
2.9 \\
2.8 \\
3.1\end{array}$ & $\begin{array}{l}5.9 \\
5.8 \\
5.6 \\
3.5 \\
2.4 \\
1.0 \\
2.9 \\
2.0\end{array}$ & $\begin{array}{r}23.6 \\
22.0 \\
13.9 \\
9.4 \\
15.9 \\
21.3 \\
15.1 \\
30.5\end{array}$ & $\begin{array}{l}16.8 \\
18.0 \\
11.6 \\
10.5 \\
15.0 \\
15.8 \\
17 \cdot 1 \\
16 \cdot 1\end{array}$ & $\begin{array}{l}2.4 \\
3.5 \\
1.8 \\
1.8 \\
2.5 \\
4.2 \\
3.1 \\
4.7\end{array}$ & $\begin{array}{l}2.1 \\
2.1 \\
2.0 \\
2.5 \\
4.5 \\
6.0 \\
3.3 \\
2.1\end{array}$ \\
\hline & & $\begin{array}{r}69 \\
3\end{array}$ & $\begin{array}{r}66 \\
3\end{array}$ & $\begin{array}{r}57 \\
4\end{array}$ & $\begin{array}{r}49 \\
4\end{array}$ & $\begin{array}{r}12 \\
1\end{array}$ & $\begin{array}{r}10 \\
1\end{array}$ & $\begin{array}{l}7 \\
2\end{array}$ & $\begin{array}{l}6 \\
1\end{array}$ & $\begin{array}{r}10.5 \\
0.9\end{array}$ & $\begin{array}{r}13.4 \\
2.5\end{array}$ & $\begin{array}{l}3.8 \\
0.5\end{array}$ & 0.3 & $\begin{array}{l}4.5 \\
0.6\end{array}$ & $\begin{array}{l}3.6 \\
0.7\end{array}$ & $\begin{array}{r}19.0 \\
2.4\end{array}$ & $\begin{array}{r}15 \cdot 1 \\
0.9\end{array}$ & $\begin{array}{l}3.0 \\
0.4\end{array}$ & $\begin{array}{l}3.1 \\
0.5\end{array}$ \\
\hline
\end{tabular}

SAP, mean systemic arterial pressure; PAP, mean pulmonary arterial pressure; LAP, mean left atrial pressure; RAP, mean right atrial SAP, mean systemic arterial pressure; PAP, mean pulmonary arterial pressure; LAP, mean left atrial pressure, RAP, mean pressure; $Q p$, pulmonary blood flow; $Q s$, systemic blood flow; $P V R$, pulmonary vascular resistance 


\section{Discussion}

This study has shown that the haemodynamic effects of hydralazine are not necessarily consistent in every patient with a large ventricular septal defect, except that a lowering of left atrial pressure has been common to them. Beekman et al. ${ }^{8}$ showed that hydralazine caused a decrease in the $Q p / Q s$ ratio in every infant with a large ventricular septal defect with no exceptions. In our study, the $Q p / Q s$ ratio was decreased by hydralazine only in patients who had low systemic blood flow and high systemic vascular resistance.

It is known that the volume of left to right shunt is determined by aortic impedance to left ventricular ejection in ventricular septal defect. ${ }^{71011} \mathrm{An}$ increase in systemic vascular resistance results in an increase in the shunt, and vice versa. This will be the case when the septal defect is restrictive, or when pulmonary vascular resistance does not respond to intervention. In a large and non-restrictive ventricular septal defect, the $Q p / Q s$ ratio is determined by the relative resistance of systemic and pulmonary vascular beds. ${ }^{12}$ This indicates that the effect of vasodilators on the $\mathrm{Qp} / \mathrm{Qs}$ ratio is dependent upon the relative responsiveness of systemic and pulmonary circulation to the drug. As shown in this study, pulmonary vascular resistance is usually higher than normal in infants with a large ventricular septal defect. In this condition, when associated with no systemic vasoconstriction, the effect of hydralazine would be more pronounced on the pulmonary circulation than on the systemic, thus resulting in an increase of the $Q p / Q s$ ratio. This is the same response as reported by Macri and Redaelli13 and Linday et al. ${ }^{14}$ It is, therefore, suspected that their subjects had the same haemodynamic characteristics as we have just described.

A large ventricular septal defect is occasionally associated with low systemic blood flow and with high systemic vascular resistance which will be manifested by clinical findings such as tachycardia, small peripheral pulse, pronounced perspiration, and a cold and pale skin. In these cases, the $\mathrm{Qp} / \mathrm{Qs}$ ratio would be largely influenced by systemic vascular resistance, and could be reduced by systemic vasodilatation. Thus, reduction of the resistance would be more prominent in the systemic circulation than in the pulmonary one. This type of response was present in the oldest patient in this study.

Reduction of the $Q p / Q s$ ratio is also observed in cases where the pulmonary vascular bed is not responsive to vasodilators. We have experienced such a patient with transposition of the great arteries associated with ventricular septal defect and pulmonary vascular obstructive disease after a palliative Mustard operation, who responded to hydralazine with a reduction of the $Q p / Q$ s ratio. A similar response would be expected in cases which have unconstricted or already dilated pulmonary vasculature, as described by Beekman et al.$^{8}$ and in the mature animal study. ${ }^{11}$

The other significant effect observed in this study was a lowering of the left atrial pressure. The fact that high left atrial pressure is often associated with tachypnoea and/or retention of carbon dioxide in patients with a large ventricular septal defect indicates that interstitial oedema of alveoli caused by an increase of pulmonary venous pressure may play a role in the respiratory problems. Thus lowering left atrial pressure should theoretically improve the gas exchange. Further clinical observation is needed to confirm this effect.

In summary, hydralazine reduced the $\mathrm{Qp} / \mathrm{Qs}$ ratio only in cases with low systemic blood flow, thus implying that it may be beneficial in those cases. This agent, however, increased the $Q p / Q s$ ratio and $Q p$ in cases which had had normal or high systemic blood flow before hydralazine. Thus, the study has shown that the effect of hydralazine is dependent upon the pretreatment haemodynamic state.

\section{References}

1 Mason DT. Afterload reduction and cardiac performance. Physiologic basis systemic vasodilators as a new approach in treatment of congestive heart failure. $\operatorname{Am~} \mathcal{F}$ Med 1978; 65: 106-25.

2 Cohn JN, Franciosa JA. Vasodilator therapy for cardiac failure. N Engl F Med 1977; 297: 27-31, 254-8.

3 Lakier JB, Khaja R, Stein PD. Rationale and use of vasodilators in the management of congestive heart failure. Am Heart $f$ 1979; 97: 519-26.

4 Chatteriee K, Parmley WW. The role of vasodilator therapy in heart failure. Prog Cardiovasc Dis 1977; 19: 201-25.

5 Greenberg BH, Massie BM, Brundage BH, Botvinick $\mathrm{EH}$, Parmley WW, Chatterjee K. Beneficial effects of hydralazine in severe mitral regurgitation. Circulation 1978; 58: 273-9.

6 Greenberg BH, DeMots H, Murphy E, Rahimtoola SH. Mechanism for improved cardiac performance with arteriolar dilators in aortic insufficiency. Circulation 1981; 63: 263-8.

7 Synhorst DP, Lauer RM, Doty DB, Brody MJ. Hemodynamic effects of vasodilator agents in dogs with experimental ventricular septal defects. Circulation 1976; 54: 472-7.

8 Beekman RH, Rocchini AR, Rosenthal A. Hemodynamic effects of hydralazine in infants with a large ventricular septal defect. Circulation 1982; 65: 523-8.

9 Lister G, Hoffman JIE, Rudolph AM. Oxygen uptake in infants and children: a simple method for measurement. Pediatrics 1974; 53: 656-62. 
10 Tanenbaum HL, Pfaff WW. Effect of pressor amines on experimental intracardiac shunts and valvular regurgitation. Dis Chest 1963; 44: 485-91.

11 Boucek MM, Chang R, Synhorst DP. Effects of prazosin (P) and hydralazine $(\mathbf{H})$ on the hemodynamics of chronically instrumented lambs with ventricular septal defect [Abstract]. Circulation 1980; 62 (suppl III): 111-5.

12 Rudolph AM, Nadas AS. The pulmonary circulation and congenital heart disease. Considerations of the role of the pulmonary circulation in certain systemic-pulmonary communications. $N$ Engl $\mathcal{F}$ Med 1962; 267: 968-74, 1022-9.
13 Macri R, Redaelli S. Vasodilators in VSDs [Letter]. Circulation 1979; 56: 329-30.

14 Linday LA, Levin AR, Klein AA, Reidenberg MM, Engle MA. Effect of vasodilators on left-to-right shunts in infants and children [Abstract]. Pediatr Res 1980; 14: 447.

Requests for reprints to Dr Makoto Nakazawa, Department of Pediatric Cardiology, The Heart Institute of Japan, 10 Kawada-cho, Shinjuku-ku, Tokyo 162, Japan. 